\title{
Effectiveness of Psychodrama on Anxiety of Multiple Sclerosis Patients
}

\author{
Saeed Dehnavi ${ }^{1^{*}}$ \\ Setareh Javaher Parde 2 \\ Hamide KhodaViren ${ }^{3}$ \\ Mahin Bajalan 4 \\ 1. MA in Clinical Psychology, Islamic Azad University of Qazvin, Iran \\ 2. MA in Clinical Psychology, Islamic Azad University of Qazvin, Iran \\ 3. MA in Clinical Psychology, Islamic Azad University of Semnan, Iran \\ 4. MA in Personality Psychology, Islamic Azad University of Karaj, Iran \\ *Email: Saeed.dehnavi@ymail.com
}

Doi:10.5901/mjss.2016.v7n4s1p150

\section{Abstract}

The aim of this study was to determine the effectiveness of unity-oriented psychodrama on MS patients' anxiety. Subjects included 20 female patients randomly assigned to experiment and control groups. Experiment group participated in 12 sessions of unity-oriented psychodrama, while control group received no intervention. Data was collected by Anxiety Scale, and analyzed using ANOVA with repeated measure. Results showed significant differences between two groups at posttest and follow-up, meaning unity-oriented psychodrama is effective in reducing MS patients' anxiety by helping them to feel integrated with the universe, give meaning to bitter experiences and reach a new meaning of life and death.

Keywords: psychodrama, anxiety, Multiple sclerosis

\section{Introduction}

Multiple sclerosis is a demyelinating disease of the central nervous system. That is one of the most common neurological diseases in humans. In this disease, the myelin covering of the central nervous system including the brain, spinal cord and optic nerve is damaged. The most common age of it, is the youth and it is twice as common in women (1). There are many symptoms of MS, although the cause is still unknown. The disease often occurs in people who live in northern latitudes (2). Psychological problems in multiple sclerosis patients compared to the healthy population and other chronic diseases are far more common. Empirical research literature suggests high rates of depression and frustration, increased anxiety, decreased mental well-being and quality of life and creating problems related to relationships and social role (3) they suffer higher rates of depression (4 and 5) and compared with patients with other neurological conditions or the general population, experience more anxiety (6).

This disease is the most common cause of disability in young age. Usually people get infected in their life when they try to work or raise a family. It is a lifelong process and unpredictable and complicated with the development of debilitating symptoms that significantly affects the patient's lifestyle. So not only the patient must be clinically and pathologically physiological but in terms of the impact that symptoms such as disability, symptoms such as disability, fatigue, depression and anxiety on their family life and work be taken into consideration (7).

Studies have shown that the relationship between mental health and multiple sclerosis is significant. During the study it was found that $17.9 \%$ of patients have severe physical problems and $38.8 \%$ had severe social problems, severe anxiety and depression are also at 11/2 percent and 14/9 percent of the patients (8). In addition, another study showed that quality of life was significantly lower for the patients than general population (9). Other studies show that people with MS suffer high rates of mental health problems, and they tolerate higher rates of depression (10). All these findings indicate the psychological and complex problems of MS patients.

Unity-oriented Psychology is a new approach native of Iran, based on human nature and related to Islamic mysticism and Eastern philosophy. Unity-oriented therapy approach is based on cognitive and spiritual tasks that includes a series of awareness for the unitary and meaningful connection to their world through cognitive and intuitive exercises, 
for example, knowledge of self and world unity and the adoption of a meaningful life in a world of targeted orbit; The awareness on the safety and value and importance of the individual in the world increases through their unique understanding of the role of connected and eternal life and promote the value and integrity of self and confidence and trust in the universe. Individual in the world has meaning and through this understanding of the importance of the unique person in the world is highlighted [11].

Psychodrama is a branch of art therapy which counts as a new view in the field of psychotherapy. This way as a therapeutic tool in the early 1920s suggested by Moreno that was one of the discoveries in connection with the conflict in individual in order to rescue the suppressed feelings. Psychodrama based on hypothesis of Monroe, is impromptu, and is inversely related to anxiety. In other words, when the person is more spontaneous, he has less anxiety, psychodrama and role playing is an effective treatment for anxiety (12).

Previous studies have shown that Psychodrama is effective for the treatment of moderate depression (13), the treatment of addicted girls at risk of sexual abuse for coping with trauma (14) and to reduce the amount of somatization, anxiety, depression and overall general health promotion (15).

In unity oriented outlook all world is smart and there is no the slightest chance involved. All components and coarse particulate matter are intelligent body of a united world and the aware and powerful integrated nature of God upon their existence to some degree in terms of structure and hierarchical enjoy are connected to the presence of the Lord. The meaning of freedom and creativity in the approach to unity is growth and prosperity in the originality and nature hidden inside us. In unity oriented approach all creatures are reflected in the mirror of the only Lord. And all are divine light and radiation from the unique God and have unitary meaning and purpose and every human being moves in the best position to complete the experience and self-actualization and crises and incidents are levels of transformation and selfrealization (16).

In dynamic and experiential psychodrama therapy it is emphasized on the present and the "here and now" even when a person tells his problems from long ago. In this way o therapy, therapist, not just through dialogue but with "action" and "active view" attempts the identification of the structure of personality, interpersonal communication, internal conflicts and patient's emotional issues and provide insight, character development and treatment (17). Although psychodrama has its own concepts and has common roots with group psychotherapy but we must bear in mind that is not unique theory, it can be considered a methodology that offers beneficial ways to understand human nature and human relations (18).

In Psychotherapy Interventions cultural characteristics of the patient and the social implications have a significant impact on the effectiveness of the treatment. According to Iranian cultural and religious preparation of the concept of unity and connection with its spiritual implications, the present study connects cognitive tasks of this approach to Psychodrama techniques and examines the impact, since this study intends to investigate the effectiveness of unity oriented psychodrama as a traditional remedy for anxiety in multiple sclerosis patients.

\section{Method}

This study is a quasi-experimental design with pretest, posttest with control group. The study population consisted of all members of the MS Society of Iran in Tehran in the spring of 2014 and a sample of 20 members of the Association that were selected by available sampling method and randomly divided into two groups of experimental and control.

Inclusion criteria were: diagnosis of MS is relapsing-suppression, being on suppression stage, independent of the wheelchair, at least having diploma, not using psychotropic drugs and psychological treatments during the study, the same previous use of training forum for all participants, age between 20 to 50 years, willing participation in the project, Lack of other acute or chronic mental or physical disorders, not having trouble hearing and speech, Female gender. The exclusion criteria of the study were: wheelchair dependence, lack of willingness to participate in the project, more than three days absence.

Then, after obtaining the written consent form the experimental group was invited to participate in meetings of psychodrama based on unity oriented approach. Intervention with the experimental group as a group was implemented for 12 sessions of 2 hours during six weeks on the principles of psychodrama based on unity oriented approach. After the ending of seasons the post-test was performed on experimental group.

\section{Implementation Method}

In the first session while familiarizing the members with each other, description of psychodrama and techniques, psychological unity oriented theory, rules and structure of the meetings has been stated. In the second session while 
building confidence and training of speech, it was tried to establish a dialogue and state the problem. In second to sixth sessions the emphasis was on practice to focus, the use of non-verbal ways of expressing awareness of emotion, familiarity with the concepts of "unity in diversity" and "diversity in unity", familiarity with languages of body and soul and discussion of soul and body in the form of psychodrama To connect the circuit unity to world exercises to understand the immortality of the soul, emotional and mental connection with a life source.

Members of the meetings in the form of rehearsal became aware of the emotions and memories. In the seventh to eleventh sessions the focus was on engaging members recounting their problems in the form of role playing and psychodrama techniques and participation as a helper to assist in the implementation process behavioral exercises with understanding their unitary presence and unique understanding of the self. During the meetings additional techniques, role reversal, mirror technology, future projection techniques, monologues and self-actualization were used.

In the twelfth session by reviewing and summarizing meetings and sharing and sharing the achievements of therapy sessions, members ended the sessions to continue their life. In analyzing the data, descriptive statistics and ANOVA test was used.

\section{Research Tools}

Beck Anxiety Inventory: (BAl)

The questionnaire has 21 article that measures anxiety on a scale of zero to 63 with high internal validity, high reliability. Three items assess the subject of anxious, three items for special fear, fourteen items for autonomic symptoms and hyperactivity and stress-related anxiety. The internal consistency and reliability with retest after a week is. /75 (18). In this study, the reliability of the -retest interval of two months was. / 89. And internal consistency, of Cronbach's Alpha was. 188.

\section{Findings}

Data obtained using appropriate methods of descriptive statistics such as mean and standard deviation are described. To test the hypothesis one-way analysis of variance was used.

Table 1. Descriptive indices anxiety in experimental and control groups

\begin{tabular}{cccccc}
\hline \multirow{2}{*}{ Group } & \multicolumn{2}{c}{ Pre-test } & & \multicolumn{2}{c}{ Post-test } \\
\cline { 2 - 3 } \cline { 5 - 6 } & $M$ & $S D$ & & $M$ & SD \\
\hline$(n=10)$ Control & $17 / 50$ & $8 / 28$ & & $19 / 30$ & $7 / 54$ \\
$(n=10)$ Experimental & $17 / 30$ & $9 / 45$ & & $9 / 25$ & $4 / 55$ \\
\hline
\end{tabular}

The results in Table 1 indicate that the variable of anxiety Pretest to post-test scores of the experimental group decreased while the average scores from pretest to post-test control group had a slight increase.

Table 2. The results of ANOVA for comparison of the scores of pre-test and post-test, experimental and control groups

\begin{tabular}{ccccccc}
\hline Source & Sum of squares & df & Mean Square & F & Significant level & Effect size \\
\hline Group & $520 / 80$ & 2 & $400 / 260$ & $13 / 90$ &.$/ 001$ &.$/ 506$ \\
Error & $503 / 400$ & 26 & $18 / 762$ & & &
\end{tabular}

Results in Table 2 indicate; The pre-test to post-test score changes of anxiety in experimental and control groups differed significantly $(\mathrm{p}<0 / 001)$. According to the mean seen in Table 1 , the change from pretest to post-test scores in the experimental group increased and for the control group was decreased. Also it is noteworthy that the effect size of this test was about 0/506.

\section{Discussion and Conclusion}

As stated before the study aimed to investigate the effectiveness of unity oriented psychodrama as a traditional remedy for anxiety in multiple sclerosis patients. The results of this study showed that the intervention in reducing anxiety in MS patients is effective and its effectiveness is significant. 
Multiple Sclerosis with its debilitating, chronic and non-predict characteristic can cause many challenges in life. Given the young age of disease, the patients have to rethink their live programs, family and work and with the recurrence of the disease face the lack of autonomy and anxiety (7).

Unity oriented psychology as a local school and a new approach to psychotherapy community, promising to help the growing number of patients that complain about the feelings of anxiety, loneliness and lack of meaning in life. Unity oriented psychology with the a sense of connection to the world with the unique and meaningful relationship, calms the MS patients who suffer from high levels of anxiety and gives meaning to their life.

The indigenous healing practices with the deep concepts Iranian patients face during life, helps them to understand the dimensions of their existence and continuity of soul and body and how to actually build their own unique potential capacity and also by specifying the purpose of life and following it up recognize their unique values and be able to choose responsibility for their lives. Since the "why me?" is one of the most challenging questions that occupy mind of multiple sclerosis patients, achieving Unchangeable or inevitable matters in life that are based on unity and wisdom, helps the patients by accepting the disease and its bitter consequences with understanding and connection to sole source of life, look for the meaning of their lives and realize that they cannot be a passive victim of circumstances (11); This type of perception of sickness and difficulties of life and sense of control over it is a result of unity oriented world view, is very effective in tolerating hardships and coping with difficult situations in patients with multiple sclerosis.

Psychodrama therapy which is dynamic and experimental strongly emphasizes on present time and "here and now" and duty oriented approach put the human in present situation "now" with unitary and connection to only being. Basically unity means oneness and connects with the being that is in the current time, and makes the human focus on him in any situation, and accepts and creates a sense of security and peace. Even when the person talks about his distant past problems with the eternal hope he focuses on the present (16).

In psychodrama unity circuit based approach, therapist, not just through dialogue but with "action" and "active view" investigates the experience of self, internal conflicts and emotional problems of patient and provides safety and comfort and trust for them. The therapist, in this way, provides solutions so that eventually patients become aware of their individual and social unique role in life. Unity oriented psychodrama helps patients create meaning in their suffering and torment, whether this torment, is chronic pain and terminal illness such as multiple sclerosis; whether any other problems and suffering.

By addressing existential concepts and mental anxiety during treatment sessions, patients were given the opportunity to express their concerns and unspoken feelings in a sympathetic atmosphere and come to a new understanding of life and connect themselves to the unity oriented existence and offer themselves a new definition of being unified. And know the obstacles to harmonious living and connection to sole being, and with the sufficient and deliberate knowledge attempt to rebuild their roles and responsibilities in life.

It seems like the patients in therapy sessions focusing on different aspects of integration and unity "of soul and body" in the form of role-play, they achieved the new understanding of the dimensions of their existence and the bond between them. And with understanding the immortality of their soul and its connection with the origin of the universe, they managed to analyze and process their anxiety with unity oriented approach and achieve the necessary insight.

In treatment sessions, psychodrama techniques like role playing, role reversal, mirror technique, future-projection technique, monologue, and empty chair technique were used to express emotions and life events of the patients, also the viewpoint of the members of the intervention group became integrated with unity-oriented worldview toward the life events and found meaning and spirituality. Moreover, the adjustment of the patients was improved by meaningful acceptance and their mental well-being was strengthened.

Psychodrama based on unity oriented approach by providing new theoretical and practical basics in order to fulfill its basic aims, encourages group member s to carry out practical activities to reduce stress and help them by getting rid of the disappointment and loneliness, and connecting and bonding with life and unity oriented diversity, and a new understanding of their identity and connect with others, and find the meaning of love and value of freedom, and take maximum power to control the remaining time of life, and with experiencing this authentic and unity oriented view, free themselves from fear of death and nothingness and with consistent understanding of themselves and compliance with hardships and difficulties, experienced their life in a meaningful way.

\section{Study Limitations}

Single-sex sample and small sample size that provides a problem for generalized results, also short distance of keeping track. It is suggested that for future studies of both sexes in a larger volume samples be used. And also it is recommended that research projects on MS patients due to their sensitivity to heat, be done in cold seasons. 


\section{References}

1- Holland, N. J., \& Halper, J. (2005). Multiple sclerosis: A self-care guide to wellness. New York: Demos Medical Publishing.

2- Rapaport, B., \& Karceski, S. (2012). Multiple sclerosis and stress. Neurology, 79(5), e47-e49.

3- Liu, X. J., Ye, H. X., Li, W. P., Dai, R., Chen, D., \& Jin, M. (2009). Relationship between psychosocial factors and onset of multiple sclerosis. European neurology, 62(3), 130-136.

4- Janssens, A. C. J. W., Doorn, P. A., Boer, J. B., Meche, F. G. A., Passchier, J., \& Hintzen, R. Q. (2003). Impact of recently diagnosed multiple sclerosis on quality of life, anxiety, depression and distress of patients and partners. Acta Neurologica Scandinavica, 108(6), 389-395.

5- Siegert, R. J., \& Abernethy, D. A. (2005). Depression in multiple sclerosis: a review. Journal of Neurology, Neurosurgery \& Psychiatry, 76(4), 469-475.

6- Zorzon, M., de Masi, R., Nasuelli, D., Ukmar, M., Mucelli, R. P., Cazzato, G., ... \& Zivadinov, R. (2001). Depression and anxiety in multiple sclerosis. A clinical and MRI study in 95 subjects. Journal of neurology, 248(5), 416-421.

7- Rapaport, B., \& Karceski, S. (2012). Multiple sclerosis and stress. Neurology, 79(5), e47-e49.

Russell, C. S., White, M. B., \& White, C. P. (2006). Why me? Why now? Why multiple sclerosis: Making meaning and perceived quality of life in a Midwestern sample of patients with multiple sclerosis. Families, Systems, \& Health, 24(1), 65.

8- Mahmoudi Alami Gh. Nasiri A. Neaz Azeri K. Mental health in MS patients in Mazandaran province. Nurse educator MA thesis Islamic Azad University of Sari. 1386. [In Persian]

9- Nejat S. Quality of life in patients with MS of Tehran compared with healthy population of Tehran. Iranian journal Epidemiology. Volume 1, Number 4; (In 1385). pp 24-19. [In Persian]

10- Siergert RJ. Abernethy DA. Depression in multiple sclerosis: A review. Journal of Neurology, Neurosurgery \& Psychiatry; (2005). 76:469-475.

11- Zadeh Mohammadi, Ali (2011). رو انشناسى وحدت مدار [Unity-oriented Psychology]. Tehran, Iran: Qatreh Publications.

12- Chesner, A. (1994). Drama Therapy and Psychodrama Similarities and Differences. In S. Jennings, A. Cattanach, S. Mitchell, A. Chesner, \& B. Meldrum (Eds). The Handbook of Dramatherapy (pp. 114-132). London: Routledge.

13- Hamamci Z. Integrating psychodrama and cognitive behavioral therapy to treat moderate depression. The Arts in Psychotherapy.2006. 33. pp: 199-207.

14-Somov PG. A psychodrama group for substance use relapse prevention training. The Arts in Psychotherapy, 2008. 35. pp: 151161.

15- Ghasempoor A, Mahdavi A. Survey Effect of psychodrama on promoting public health. Journal of Rahpooye of Art 2010.3(9).pp:11-20. [Text in Persian].

16- Zadeh Mohammadi, Ali (2014). جهانشناسى وحدت مدار [Unity-oriented Worldview]. Tehran, Iran: Qatreh Publications.

17- Blatner, A. (1996). Acting-in: Practical applications of psychodramatic methods. Springer Publishing Company.

18- Beck, A. T. \& Streer, R. A. (1984). Beck Depression Inventory. The Psychological Corporation: New York. 